\title{
Development of Mango and Tomato Paste and It's Physico-Chemical Characterization
}

\author{
Dakshan Kumar Nethaji ${ }^{1}$, Sakamuri Suresh ${ }^{2}$, J. Esther Hellan Prasanna ${ }^{1}$, Dr. V. Vijayagopal ${ }^{1}$, \\ Dr. Gurusamy Ramesh ${ }^{3}$ \\ ${ }^{1}$ Department of Food Technology, JCT College of Engineering and Technology, Coimbatore, Tamilnadu, India \\ ${ }^{2}$ Quality Manager, Sree Sannidhi Foods Pvt Ltd, Chittoor, Andhra Pradesh, India \\ ${ }^{3}$ Department of Mechanical Engineering, JCT College of Engineering and Technology, Coimbatore, Tamilnadu, \\ India
}

\section{Article Info \\ Volume 7, Issue 5 \\ Page Number : 165-171 \\ Publication Issue : \\ September-October-2020}

\section{Article History}

Accepted : 20 Sep 2020

Published : 30 Sep 2020

\section{ABSTRACT}

Mangoes are most widely used in cuisine. The Soil requirement for cultivation of Mango tree is a hardy perennial and evergreen tree and it can be grown on a wide range of soils. Value added product such as Milk Shakes can be obtained from fresh pulp of Mango which acts as an excellent source of Vitamin-A and flavonoids. Similar to that high quality Tomato product can be prepared from tomato pulp by using uniformly ripened, red colour tomato. Thus Tomato is nutritious and mostly eaten as processed fruit. So the importance of Climatic Fruit in food industries for the manufacturing of value added Product has received great attention. So the objective of present study is to analyse the composition of mango and tomato and to develop the pulp, and also to know its shelf life which favour the health benefits.

Keywords : Mango, Tomato, Paste, Pulp, Shelf life, Microbial Analysis.

\section{INTRODUCTION}

Mango (Magnifera indica $L$ ) is one of the popular tropical fruit which belongs to the family Anacardiaceae. Among the tropical fruits, Mangoes are commercially grown in more than 80 countries according to the climatic and Soil Condition.

Mango trees usually grow upto $35-40 \mathrm{~m}$ tall, with a radius of $10 \mathrm{~m}$. The trees are long- lived, as some specimens still fruit after 300 years. There are different types of named mango cultivars. In mango orchards, several cultivars are often grown in order to improve pollination. The 'Alphonso' is the common monoembryonic cultivar, which is considered as an important export product. It is also known as "The King of Mangoes".

Tomato (Solanum lycopersicum L) is common and most popular fruit cultivated across the world. Tomato species is originated in western South America and Central America. It is comparatively quite hard and highly Nutritive Fruit. It shines with 
other fruit crops in productivity, adaptability, Minerals \& vitamin C content.

As a source of different types of vitamins, minerals and phenolic antioxidants, tomato can be ranked as the first comparing all the fruits and vegetables. The richest sources of the antioxidant lycopene which possibly cares the cells from oxidants that have been associated to cancer can be obtained from either Fresh or processed tomatoes. Tomatoes contain high amounts of $\beta$-carotene, niacin, riboflavin, thiamine, magnesium, iron, phosphorus, potassium and sodium.

Pulp can be defined as a mass of pressed fresh fruit or vegetable matter which can't be suitable for immediate consumption. Pulp is mushy but can contain fruit parts or sometimes even whole fruits. It must always be soft, moist part of a fruit with a proper consistency.

The retaining property of the nutrients in fruit is more in the fruit pulp and thus preferred in various food and beverage products. Fruit pulp is more beneficial as compared to juice concentrate since it is rich in fiber content due to the presence of crushed membrane of the fruit.

Pulp is used for the production of jams, marmalades, jellys, sweets, drinks and fillings of baked goods. The pulp can be treated with the sorbic acid or sulphuric acid during processing for the preservation purpose. The main factor that drives the adoption of the fruit pulp is the Shelf life. The Shelf life of Fruit pulp is longer than the Fresh fruit. The Longer Storage life without the alteration to the natural content and Flavour is the main factor that leads to the increasing the global market demand for the fruit pulp.

The specific objectives of this study were as follows:

To analyze proximate composition of mango and tomato and to develop pulp.

To know the shelf life and acceptability health benefits of the product.

\section{METHODOLOGY}

Mango pulp is prepared by well ripened Mango, which has been checked during the unloading of mango near the Ripening Chamber. The Ripening Chamber was cleaned with the help of water jet pump before unloading the fruit. After drying the Chamber, the fruits are unloaded according to the capacity of Chamber for artificial ripening with the help of Ethylene gas.

The Ripened Mangoes is brought to the manufacturing unit near the washing area after 24 Hours from Chamber. Acceptable Mangoes were passed through conveyor belt into the Chlorinated washing Tank at $10 \mathrm{ppm}$. The fruits were passed from Primary Fruit washing tank into the Secondary Washing tank. Secondary Washing tank helps to remove chlorine residue from Fruit surface. These washed fruit is transferred to the cutting table where the tip and damaged portion of fruit is removed with the help of stainless steel knife. Then fruit is passed into the destoner were it scoops out the pulp by removing stone and the peels from the fruit. The Pulp is collected in Pulp Collection Tank. The Pulp is heated at $60^{\circ} \mathrm{C}$ in a heat exchanger with the help of hot water. The Sample is taken to check physico chemical analysis such as Brix, Acidity, $\mathrm{pH}$, etc initially. The Raw Pulp is passed through Decanter/separator to minimize Black or Brown Particles. If desired Acidity is not yet attained, add required amount of Citric acid monohydrate in the standardization tank. Now Transfer Pulp to Evaporator feed tank.

The Pulp is transferred to First effect of evaporator where it's heated at $60^{\circ} \mathrm{C}$ under vacuum to increase the brix. Then the pulp is transferred to Second effect of evaporator and it's heated with help of steam at $70^{\circ} \mathrm{C}$ under vacuum to achieve final brix. After desired brix is achieved, the pulp is transferred out of evaporator and is passed to sterilization tank. 
Sterilization temperature is maintained from $110^{\circ} \mathrm{C}$ $115^{\circ} \mathrm{C}$ with the help of hot water in tubular heat exchanger. After reaching the Sterilization temperature, product is further passed through module of heat exchanger where pulp is allowed for cooling. Once temperature gets achieved, the pulp is filled in sterile aseptic bag inside the drum and it's stored for manufacturing of value added product.

Tomato paste was prepared by buying fresh tomato from the famers and it's unloaded into the crates for the preparation of tomato paste. The Crates have been stored into the ripening chamber. During Processing the Tomatoes was taken from the ripening chamber and it's passed through washing tank to foreign substance present above the surface of tomato.

The Sorting of tomato was done after washing by passing the fruit into the conveyor belt. These Tomatoes was passed through the fruit miller where the tomato is been crushed and the outer skin is removed. The Paste is heated to $75^{\circ} \mathrm{C}$ in a preheater. Then the paste is transferred to the pulp finisher to filter the paste. The filtered paste is passed to the standardization tank to standardize the paste. The standardized Paste is transferred to the Evaporator feed tank.

The paste is passed to the first effect of the evaporator and it is heated at $75^{\circ} \mathrm{C}$ to increase the brix partially. After heating, the paste is moved to the second effect of the evaporator where it is heated under vacuum at $80^{\circ} \mathrm{C}$ to achieve the required brix. After the desired brix is achieved, the paste is transferred out to the sterilization balance tank and it is heated at $108^{\circ} \mathrm{C}-115^{\circ} \mathrm{C}$. Once required filling temperature gets attained after cooling, normally $35^{\circ} \mathrm{C}-38^{\circ} \mathrm{C}$, the paste is been filled in aseptic bag inside the drum and it is stored for further processing.

\section{PHYSICO-CHEMICAL ANALYSIS OF PULP:}

$\%$ of Total acid $=\frac{\text { Titre } \times \text { Normality of NaoH X Eq.Wt of Citric acid X } 100}{\text { Weight of Sample X } 1000}$

Determination of Acidity: Weigh 1gm of the sample in a conical flask. Add $3 \mathrm{ml}$ of distilled water and mix well. Add 2-3 of Phenolphthalein indicator into the sample. Titrate against $0.1 \mathrm{NaoH}$ Solution till the end point of light pink colour is achieved.

Determination of Brix. Clean the surface of the Refracto meter with double distilled water and adjust to zero brix. After adjustment wipe out distilled water and add 2-3 drop of the pulp over the surface of the Brix meter .Close the coverlid and press the read bottom and note the reading on the display screen.

Determination of Consistency: Place the consistometer on a plain surface and close the gate of the consistometer. Fill the sample in the sample store block. Open the gate of the consistometer and observe the flow for 30 seconds. Note the reading of the flow rate after 30 seconds.

Determination of $\mathrm{pH}$ : Clean the $\mathrm{pH}$ meter Electrode with the distilled water. After wiping the water, dip the electrode in $\mathrm{pH}$ buffer Standard solution and adjust the $\mathrm{pH}$ as per the Standard solution range. Clean and wipe the $\mathrm{pH}$ meter with distilled water. Take sample in a beaker and dip the electrode into it and note the reading.

\section{Determination of Black / Brown Particle. Keep a} transparent glass plate on a plain white surface. Weigh $10 \mathrm{gm}$ of the sample and pour the same on the glass plate. Place another glass plate above that and press smoothly the glass plate and spread the pulp between the two glass plate without air bubble. By Visual examination count the number of black and brown particles. 


\section{SHELF LIFE:}

Shelf Life varies between different types of food products according to the type of processing methods. Shelf life also depends on the temperature of the product during which it is been processed and stored. Microbiological and Sensory analysis are the two main shelf life tests which ensures that the pulp can be stored for different duration at different temperature.

Normally, Tomato Paste is been stored for 24 months at ambient temperature. But mango pulp can been stored for 18 Months at ambient temperature and upto 24 months in cold storage temperature. The cold storage condition always helps the pulp to prolong the shelf life and prevent the microbial spoilage.

\section{MICROBIAL ANALYSIS:}

Detection of Escherichia coli (E.coli): An appropriate weight of EMB media agar taken in the plates and dissolved in distilled water. Prepared media is kept for autoclaving at $120^{\circ} \mathrm{C}$ for $20 \mathrm{~min}$. And petri plates are placed inside the laminar flow unit for sterilization at $155^{\circ} \mathrm{C}-160^{\circ} \mathrm{C}$ for $1 \mathrm{~h}$. After sterilizing process, media is allowed to cool at specified temperature. For Fruit concentrates, the sample should be prepared always as a homogenate.

Two types of dilutions was prepared and selected for plating. Dilution should always in a manner that they would able to produce easy countable number of colonies on each plate. Now, Transfer $1 \mathrm{ml}$ of selected dilution to each of two petri dishes required per sample and pour $15 \mathrm{ml}$ of melted agar into each plate. After pouring the medium, mix sample thoroughly with agar and allowed agar for solidification. Invert the plate after solidification and place them in the bacteriological incubator at $37 \pm 1^{\circ} \mathrm{C}$. The plates should be always dry nor be very wet. Thus the plate is examined for $24 \mathrm{~h}$ and presence / absence of E.coli is noted.

Detection of Salmonella: Weigh $25 \mathrm{~g}$ of sample into the sterile container and add $220 \mathrm{ml}$ of sterile buffered peptone water into it. Blend them for $5 \mathrm{~min}$ and transfer homogenized mixture to screw cap jar. Let it stand for $65 \pm 5 \mathrm{~min}$ at room temperature. Mix mixture well and incubate them at $35^{\circ} \mathrm{C}$ for $24 \mathrm{~h}$. Transfer $1 \mathrm{ml}$ of mixture to $10 \mathrm{ml}$ of Macconkey broth and incubate them at $35^{\circ} \mathrm{C}$ for $25 \pm 2 \mathrm{~h}$. After incubation streak a loopful incubated sample from Macconkey broth to Xylose Lysine deoxycholate agar and Macconkey agar and SS agar. Incubate the plates at $35^{\circ} \mathrm{C}$ for 24 hours. After incubation examine the plates for presence of Salmonella.

\section{RESULTS AND DISCUSSION}

\section{Physico Chemical Analysis of Mango Pulp}

\begin{tabular}{|c|c|c|c|c|}
\hline S.NO & TYPE OF ANALYSIS & TRIAL 1 & TRAIL 2 & TRAIL 3 \\
\hline 1 & Acidity, \%CA & 0.68 & 0.71 & 0.69 \\
\hline 2 & Brix, ${ }^{\circ} \mathrm{B}$ & 21.06 & 21.15 & 21.76 \\
\hline 3 & Consistency & 4.0 & 4.3 & 4.2 \\
\hline 4 & $\mathrm{pH}$ & 3.87 & 3.88 & 3.85 \\
\hline 5 & Black Specks & $\mathrm{NL}$ & $\mathrm{NIL}$ & $\mathrm{NIL}$ \\
\hline 6 & Brown Specks & 03 & 02 & 05 \\
\hline 7 & Taste & $\begin{array}{c}\text { Characteristics of } \\
\text { Totapuri Mango }\end{array}$ & $\begin{array}{c}\text { Characteristics of } \\
\text { Totapuri Mango }\end{array}$ & $\begin{array}{c}\text { Characteristics of } \\
\text { Totapuri Mango }\end{array}$ \\
\hline 8 & Appearance & Homogenous & Homogenous & Homogenous \\
\hline 9 & Colour & Golden Yellow & Golden Yellow & Golden Yellow \\
\hline 10 & Flavour & $\begin{array}{c}\text { Typical of Natural } \\
\text { Totapuri Mango }\end{array}$ & $\begin{array}{c}\text { Typical of Natural } \\
\text { Totapuri Mango }\end{array}$ & $\begin{array}{c}\text { Typical of Natural } \\
\text { Totapuri Mango }\end{array}$ \\
\hline
\end{tabular}

\section{Physico Chemical Analysis of Tomato Paste}

\begin{tabular}{|c|c|c|c|c|}
\hline S.NO & TYPE OF ANALYSIS & TRIAL 1 & TRAIl 2 & TRAII 3 \\
\hline 1 & Acidity, \%CA & 2.23 & 2.18 & 2.26 \\
\hline 2 & Brix, ${ }^{\circ} \mathrm{B}$ & 28.07 & 28.19 & 28.39 \\
\hline 3 & Consistency & 5.9 & 6.2 & 6.0 \\
\hline 4 & $\mathrm{pH}$ & 3.90 & 3.94 & 3.87 \\
\hline 5 & Black Specks & NIL & 01 & NIL \\
\hline 6 & Brown Specks & 04 & 02 & 03 \\
\hline 7 & Taste & $\begin{array}{c}\text { Characteristics } \\
\text { Tomato Paste }\end{array}$ & $\begin{array}{c}\text { Characteristics } \\
\text { Tomato Paste }\end{array}$ & $\begin{array}{c}\text { Characteristics } \\
\text { Tomato Paste }\end{array}$ \\
\hline 8 & Appearance & Homogenous & Homogenous & Homogenous \\
\hline 9 & Colour & Red Tomato Colour & Red Tomato Colour & Red Tomato Colour \\
\hline 10 & Flavour & $\begin{array}{c}\text { Typical Tomato } \\
\text { Flavour }\end{array}$ & $\begin{array}{c}\text { Typical Tomato } \\
\text { Flavour }\end{array}$ & $\begin{array}{c}\text { Typical Tomato } \\
\text { Flavour }\end{array}$ \\
\hline
\end{tabular}




\section{Microbial Analysis of Mango and Tomato Pulp:}

\begin{tabular}{|c|c|c|c|c|}
\hline S.NO & $\begin{array}{c}\text { TYPE OF MICROBIAL } \\
\text { ANALYSIS }\end{array}$ & TRIAL 1 & TRAIL 2 & TRAIL 3 \\
\hline 1 & E.coli & NIL & NIL & NIL \\
\hline 2 & Salmonella & NIL & NIL & NIL \\
\hline
\end{tabular}

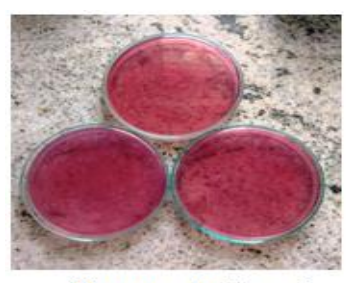

Measurement of Zone of for Mango Pulp
.

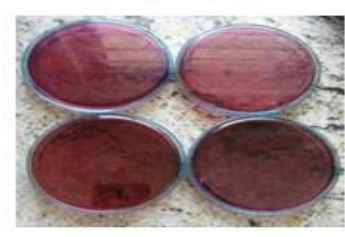

Measurement of Zone of Inhibition using Escherichia coli for Tomato Pulp

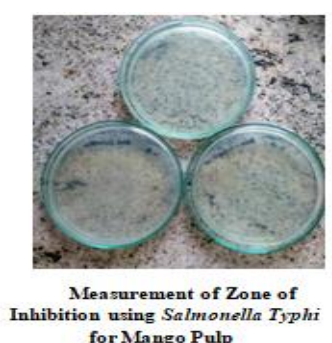
for Mango Pulp



for Tomato Pulp

\section{Health Benefits of Mango Pulp:}

Maintain Heart Health: Mango Pulp contains high amounts Nutrients such as Magnesium and potassium. Thus it can help to maintain a healthy pulse and regulate blood pressure.

Maintaining of Eye condition: Mango Pulp has antioxidant such as lutein and zeaxanthin which accumulate in the retina of the eye that prevents absorbing excess light and harmful blue light.

Improves Hair and Skin condition: Vitamin A is high in mango pulp improves the growth of hair and skin condition. The structure of the skin can be attained by Collagen, a Protein that is present in the mango pulp.

\section{Health Benefits of Tomato Paste:}

Improves immunity: Tomato Paste contains high amount of Vitamin C and Vitamin K content which improves immunity and keeps body healthy.

Good for pregnant mothers: Intake of tomato paste during pregnancy may help protect newborn from neurological disorder, since it contain high amount of contain Folic acid.

Lowers risk of cancer: Vitamin C and antioxidants like lycopene are rich in Tomato. Thus eating Tomato and its paste can protect the cells from damage and reduce cancer.

\section{CONCLUSION}

The Nature has blessed us with a wonderful flora and fauna, which has made our life beautiful. One of these wonder is a Mango and Tomato fruit.

Mango is one of the climacteric fruit which has a sweet taste that has different types of varieties according to the soil condition. It is liked by people of all age groups. Mango fruit has a short shelf life. Medicinal properties of Mango are due to chemical constituents such as polyphenols, Mangifera, and glycoside Saponin etc. The various plant of mango plant acts as an excellent nutrient which is useful in the management of many diseases like ulcer, kidney stone, diabetes, diarrhea, etc. It can also be used as diuretic, to promote eye health and also to lowers cholesterol. Storage temperature is also an another key factor in conserving Mango, since these fruit are chilling sensitive and thus special care must be taken when cold storage is used. It is commonly consumed as one of the natural energy booster as it contains fructose content.

Tomato is also an edible fruit that requires careful handling after harvest in order to maintain quality, extend shelf life \& also to allow transport to markets outside the area of production. Production of Tomato in India's is second in the world; hence the market 
value in India is comparatively less. Tomato as number of Health benefits comparing to other Fruits.

Thus value added product such as Pulp can be made from mango and tomato fruit which can be available throughout the year and it is highly accepted all over the world by consumers since it has high health benefits.

Hence the value added product preparation from Mango and Tomato is beneficial.

\section{CONCLUSION}

The Nature has blessed us with a wonderful flora and fauna, which has made our life beautiful. One of these wonder is a Mango and Tomato fruit.

Mango is one of the climacteric fruit which has a sweet taste that has different types of varieties according to the soil condition. It is liked by people of all age groups. Mango fruit has a short shelf life. Medicinal properties of Mango are due to chemical constituents such as polyphenols, Mangifera, and glycoside Saponin etc. The various plant of mango plant acts as an excellent nutrient which is useful in the management of many diseases like ulcer, kidney stone, diabetes, diarrhea, etc. It can also be used as diuretic, to promote eye health and also to lowers cholesterol. Storage temperature is also an another key factor in conserving Mango, since these fruit are chilling sensitive and thus special care must be taken when cold storage is used. It is commonly consumed as one of the natural energy booster as it contains fructose content.

Tomato is also an edible fruit that requires careful handling after harvest in order to maintain quality, extend shelf life \& also to allow transport to markets outside the area of production. Production of Tomato in India's is second in the world; hence the market value in India is comparatively less. Tomato as number of Health benefits comparing to other Fruits.

Thus value added product such as Pulp can be made from mango and tomato fruit which can be available throughout the year and it is highly accepted all over the world by consumers since it has high health benefits.

Hence the value added product preparation from Mango and Tomato is beneficial.

\section{REFERENCES}

[1]. Datey SP, Raut.V.U. Physico-chemical changes in mango pulp during ambient storage in glass containers. International Journal of Applied agricultural \& Horticulture Sciences. 2009, 22,713-717.

[2]. Alaguselvi K, Ramanathan M, Jayashree E.Concentration of mango pulp by thin layer hot air method. J Food Science Technology. 2009, 46,350-353.

[3]. Pelegrine D.H, Silva F.C, Gasparetto C.A, Rheological behaviour of pineapple and mango pulp. Lebensm.-Wiss Technology. 2002, 35, 645648.

[4]. Ruben Perez Pulido, Jose Grande Burgos, Antonio Galvez, Rosario Lucas. Changes in bacterial diversity of refrigerated mango pulp before and after treatment by high hydrostatic pressure. J Food Science and Technology. 2017, 27, 289-295.

[5]. Giovanelli G, Lavelli V. Evaluation of heat and oxidative damage during storage of processed tomato products. I. Study of heat damage indices. J. Sci. Food Agric. 2002, 82, 1263-1267.

[6]. Giovanelli G, Lavelli V. Evaluation of heat and oxidative damage during storage of processed tomato products. I. Study of heat damage indices. J. Sci. Food Agric. 2002, 82, 1263-1267. 
[7]. C.Y.Wang, B.H.Chen.Tomato pulp as source for the production of lycopene powder containing high proportion of cis-isomers. J. Food Research and technology.2006, 222, 341-353.

[8]. Porretta S, Sandel L, Crucitti P.M, Poli G, Attolini M.G. Comparison of the main analytical methods used in quality control of tomato paste, International Journal of food science and technology.1992, 27, 145-152.

[9]. Suvendu Bhattacharya, N.K.Rastogi. Rheological properties of enzyme-treated mango pulp, Journal of Engineering. 1998, 36(3), 249-262.

[10].Shi-Ying X.U, Shoemaker C.F. and Luh B.S. Effect of break temperature on rheological properties and microstructure of tomato juices and pastes, Journal of food Science. 1986, 51(2), 399-402.

[11].Giovanelli G, Lavelli V, Peri C, Pagliarini E, Zanoni B, Petrone P.The antioxidant activity of tomato. IV. Effects of storage on oxidative and heat damage. Acta Hortic. 2001,542, 221-226.

[12].P.Vijayanand, E.Deepu, S.G.Kulkarni. Physico chemical characterization and the effect of processing on the quality characteristics of Sindura, Mallika and Totapuri mango cultivars. Journal of food Science and Technology. 2013,25,176-182.

[13].Mallidis C.G, Samaras FA. Simple, rapid and sensitive method for monitoring contamination of aseptically processed tomato paste. International Journal of Food Science and Technology.1987,22,59-66.

[14].I.C.F Mores, R.M.Sampaio, N.M.Queiroz, S.M.De Salles, C.C Paschoaleti, V.H. Perez. Mango pulp (mangifera indica 1.) Preserved by hurdle Technology: physicochemical, microbiologic and Rheologic characterization. Journal of Food Processing and Preservation. 2011,35, 610-614.

[15].Bhattacharya S.Yield stress and time-dependent rheological properties of mango pulp. Journal of Food Science. 1999,64, 1029-1033.
[16].P.Surendra Naidu.The Study on Economics of Mango Processing in Chittor District. Indian Journal of Applied Research. 2014,39-42.

[17].Baloch W.A, Khan S. Influence of chemical additives on the stability of dried tomato powder. Int. J. Food Science Technology.1997,32,117-120.

[18].M.D. Khairul Islam, M.Z.H. Khan, M, A.R.Sarkar, Nurul Absar \& S. K. Sarkar. Changes in Acidity, TSS, and Sugar Content at Different Storage Periods of the Postharvest Mango (Mangifera indica L.) Influenced by Bavistin DF, 2013,43, 42-49.

[19].Gabriella Giovanelli \& Angela Paradiso.Stability of Dried and Intermediate Moisture Tomato Pulp during Storage. Journal of Agricultural and Food Chemistry. 2002,50, 7277-7281

\section{Cite this article as :}

Dakshan Kumar Nethaji, Sakamuri Suresh, J. Esther Hellan Prasanna, Dr. V. Vijayagopal, Dr. Gurusamy Ramesh, "Development of Mango and Tomato Paste and It's Physico-Chemical Characterization ", International Journal of Scientific Research in Science and Technology (IJSRST), Online ISSN : 2395-602X, Print ISSN : 2395-6011, Volume 7 Issue 5, pp. 165-171, September-October 2020. Available at doi : https://doi.org/10.32628/IJSRST207537 Journal URL : http://ijsrst.com/IJSRST207537 